\title{
A IMPORTÂNCIA DA SONDAGEM DA ESCRITA COMO INSTRUMENTO DE AVALIAÇÃO NO PERÍODO DA ALFABETIZAÇÃO
}

THE IMPORTANCE OF THE WRITING ANALYSIS AS AN INSTRUMENT OF EVALUATION IN THE PERIOD OF LITERACY

DOI: http://dx.doi.org/10.23926/RPD.2526-2149.2018.v3.n2.p453-460.id248

\section{Patrícia Rodrigues \\ Rocha \\ Mestre em Humanidades, \\ Culturas e Artes \\ (UNIGRANRIO). \\ patricia_rodrigues31@hotma \\ $\underline{\text { il.com }}$}

\section{Alessandra de Souza \\ Santos}

Mestre em Humanidades,

Culturas e Artes

(UNIGRANRIO).

alessandra.s.com@gmail.co

$\underline{\mathrm{m}}$
Resumo: Este é um relato de experiência sobre a sondagem da escrita realizada com alunos dos três primeiros anos do Ensino Fundamental, uma das atividades propostas pelas Orientadoras de Estudos (OE) do Pacto Nacional pela Alfabetização na Idade Certa (PNAIC) 2016 Polo Nova Iguaçu/RJ. Nosso objetivo com este relato é acentuar a importância da sondagem da escrita como instrumento de avaliação no período da alfabetização. Aplicamos um ditado para a escrita e leitura imediata pelos alunos das escolas em que atuamos como Orientadoras Pedagógicas. Percebemos significativos avanços na aprendizagem das crianças. Concluímos que tal prática deve ocorrer constantemente em todo o período da alfabetização de modo a mobilizar estratégias de intervenção pelo professor e o desenvolvimento dos alunos.

Palavras-chave: Avaliação. Sondagem. Alfabetização.

\begin{abstract}
This is an experience report on the writing analysis conducted with students of the first three years of elementary school, one of the activities proposed by the Trainers of Studies of the National Pact for Literacy in the Right Age (PNAIC) 2016 Polo Nova Iguaçu / RJ. Our objective with this report is to emphasize the importance of the writing analysis as an evaluation tool in the literacy period. We apply a dictation and an immediate reading of by the students of the schools in which we act as Pedagogical Consuellors. We have seen significant advances in children's learning. We concluded that such practice must occur constantly throughout the period of literacy in order to mobilize intervention strategies of the teacher for the students development.
\end{abstract}

Keywords: Evaluation. Probing. Literacy. 


\section{INTRODUÇÃO}

O Pacto Nacional pela Alfabetização na Idade Certa (PNAIC) é um compromisso formal assumido entre o governo Federal, Estados e Municípios desde 2012, com a finalidade de assegurar a alfabetização plena de todas as crianças até 8 anos ao final do $3^{\circ}$ ano do Ensino Fundamental. Um dos eixos principais do Pacto é a formação continuada dos professores e, desta forma, o município de Nova Iguaçu vem oportunizando aos seus docentes este curso. No ano de 2016 a oportunidade foi ampliada aos orientadores pedagógicos.

O presente relato apresenta experiências sobre a sondagem da escrita de alunos do Ciclo de Alfabetização da rede municipal de Nova Iguaçu, colocando em prática a metodologia do curso PNAIC 2016.

A avaliação é um tema muito discutido entre os educadores, que visam compreendê-la para seu uso adequado no processo de ensino-aprendizagem. De acordo com o caderno de apresentação do PNAIC referente à formação do professor alfabetizador (BRASIL, 2012, p. 22), é importante que se realize "uma avaliação formativa, voltada para a redefinição permanente das prioridades e planejamento contínuo do fazer pedagógico".

Além disso, Machado e Staub (2013, p. 373) afirmam que "é necessário criar instrumentos de avaliação variados para níveis de conhecimentos diversos e saber lidar com a heterogeneidade das aprendizagens, respeitando os percursos distintos e diferenciando o atendimento, instrumentos e encaminhamentos".

A sondagem, pois, é um dos instrumentos da avaliação diagnóstica que permite ao professor conhecer o que os alunos já sabem sobre o sistema alfabético e planejar atividades que os façam avançar em suas aprendizagens. Ademais, segundo Onári et al. (2011, p. 2), essa sondagem deve ser utilizada para a "constituição de grupos construtivos na sala de aula".

Conforme Aratangy e Vasconcelos (2009 apud Onári et al., 2011, p. 5), a sondagem é um ditado de palavras proposto pelo professor, envolvendo ou não o uso de frases simples para a escrita espontânea e leitura imediata pelo aluno. Ainda segundo os autores é importante que as palavras partam do cotidiano dos alunos. Além disso, segundo Batista et al. (2005, p. 56), as palavras devem ser organizadas de acordo com o número de sílabas "para [...] ter elementos adequados de análise do processo de aprendizagem e do nível de conceitualização da criança". Assim, o professor identifica o nível da escrita em que a criança se encontra e (re)planeja as suas aulas.

Para Ferreiro e Teberosky (1999 apud Onári et al., 2011, p. 2) os níveis da escrita são: pré-silábico, silábico, silábico-alfabético e alfabético. No nível pré-silábico a criança utiliza 
letras aleatórias e sem a preocupação com a quantidade delas para representar uma palavra. Já no nível silábico ela emprega uma letra (sem ou com valor sonoro) para escrever cada sílaba da palavra. O nível silábico-alfabético se caracteriza pela criança oscilar entre a hipótese silábica e alfabética, utilizando algumas sílabas completas para escrever uma palavra. No nível alfabético escreve palavras precisando apenas de ajustes ortográficos.

\section{JUSTIFICATIVA E OBJETIVOS DA EXPERIÊNCIA}

Aprender a ler e escrever com sentido se constitui o foco da alfabetização. O Sistema de Escrita Alfabética (SEA) aliado a práticas sociais de leitura e escrita deve ser trabalhado pelo professor alfabetizador com seus alunos, usando, pois, atividades significativas e instrumentos avaliativos variados para sua aquisição.

Motivadas por essas discussões e pela proposta das Orientadoras de Estudos do PNAIC 2016 em relação à sondagem e análise da escrita, desenvolvemos tal tarefa com alunos das escolas em que atuamos como Orientadoras Pedagógicas, a fim de percebermos as aprendizagens das crianças. Após análise individual, as sondagens foram discutidas pelas orientadoras formadoras e alunos do curso.

Nosso objetivo com o relato é acentuar a importância da sondagem da escrita como instrumento de avaliação no período da alfabetização, visto que sua prática auxilia o professor em seu planejamento e leva seus alunos a avançarem em suas aprendizagens.

\section{DESENVOLVIMENTO}

A sondagem foi realizada pelas Orientadoras Pedagógicas em formação, mais precisamente no início do mês de novembro de 2016 com alunos dos três primeiros anos do Ensino Fundamental das respectivas escolas de trabalho, aqui citadas como Escola A e Escola $\mathrm{X}$. As instituições estão localizadas no centro de Nova Iguaçu.

\section{A EXPERIÊNCIA NA EsCOLA A}

A sondagem na Escola A foi realizada com alunos indicados pelas professoras, que sentiam dúvidas em relação aos níveis da escrita que apresentavam. Participaram da atividade 1 aluno do $1 .^{\circ}$ ano, 3 do $2 .^{\circ}$ e 4 do $3 .^{\circ}$, totalizando 8 crianças.

Foram formulados ditados para a escrita e leitura imediata pelos alunos, aplicados conforme o ano de escolaridade que cursavam. As Figuras 1, 2 e 3 mostram as sondagens realizadas com os alunos. 

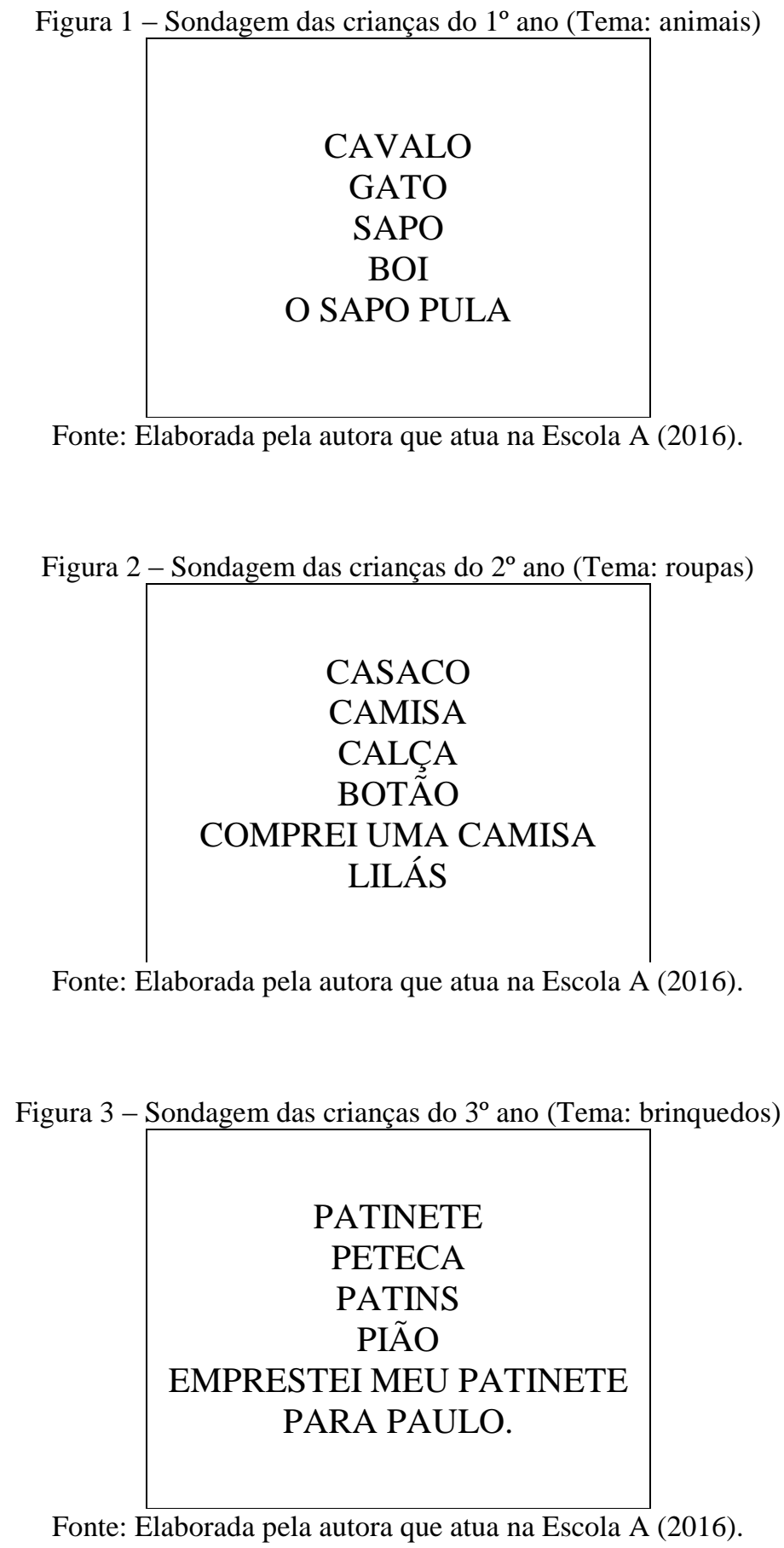

Após a atividade, constatamos 2 crianças na fase pré-silábica, 4 na silábica e 2 na silábico-alfabética. As crianças na fase pré-silábica correspondem ao 3. ${ }^{\circ}$ ano. As crianças na fase silábica variam entre $2 .^{\circ}$ e $3 .^{\circ}$ anos. Os alunos na fase silábico-alfabética encontram-se no $1 .^{\circ}$ e $2 .^{\circ}$ anos.

Levamos os ditados para a formação continuada do PNAIC, onde pudemos partilhar as impressões com as formadoras e alunos. Diante dos dados, percebemos que as crianças estão avançando em suas hipóteses de escrita, inclusive na leitura das palavras ditadas, que ocorreu 
de forma silabada e reflexiva. Pensamos coletivamente atividades para promover ainda mais o desenvolvimento desses alunos.

Retornamos à escola com as sugestões propostas e refletimos sua realização com os educandos de modo a mobilizar suas aprendizagens. A sondagem da escrita foi realizada para incentivar o professor a realizá-la mais vezes e buscar atividades mais efetivas para os seus alunos. Como assegura Hoffmam (2001 apud Onári et al., 2011, p. 6), essa avaliação possibilita "a observação permanente das manifestações de aprendizagem para proceder a uma ação educativa que otimize os percursos individuais".

\section{A EXPERIÊNCIA Na EsCOLA X}

Na Escola X foi realizada a atividade diagnóstica na turma 301 através da aplicação de um ditado com 10 palavras, com o objetivo de identificar o nível da escrita dos alunos. Neste dia, a turma estava com 25 alunos frequentando. As palavras aplicadas foram: viagem, geladeira, biscoito, porta, sofá, relógio, jogo, chutar, maleta, professora. Durante a aplicação observou-se que alguns alunos tiveram dificuldades em algumas palavras, como: professora, chutar, porta, relógio.

Quanto aos resultados, 1 aluno encontra-se na fase pré-silábica, escrevendo as palavras com quantidade e repertório variáveis e presença de valor sonoro no início ou no final delas. Outro caso é de 1 aluno que está na fase silábico-alfabética, onde ora escreve uma letra para representar a sílaba, ora grafa a sílaba completa, tendo maior dificuldade nas sílabas complexas.

Nesta turma temos 5 crianças que estão na fase alfabética, compreendendo o sistema de escrita com produções alfabéticas, mas não observando as convenções ortográficas. Temos 4 crianças na fase alfabética em que suas produções apresentam algumas convenções ortográficas e outro grupo com 14 na etapa alfabética compreendendo o sistema de escrita, produzindo e observando os acordos ortográficos.

Após recolher o ditado, colocamos as palavras no quadro para apresentá-las a turma. A partir desse momento realizamos uma conversa informal direcionando essas palavras ao contexto. Enquanto a professora da turma realizava esse trabalho com os alunos em círculo, chamamos cada um deles para ler o seu ditado, realizando desta forma o diagnóstico da leitura. Como resultado, 14 alunos realizaram a leitura de todas as palavras; 9 a fizeram através da silabação com poucas dificuldades e 2 alunos na fase inicial identificaram letras soltas e algumas sílabas.

Seguem, abaixo, evidências das estratégias realizadas. 
Figura 4 - Ditado realizado com os alunos da turma 301

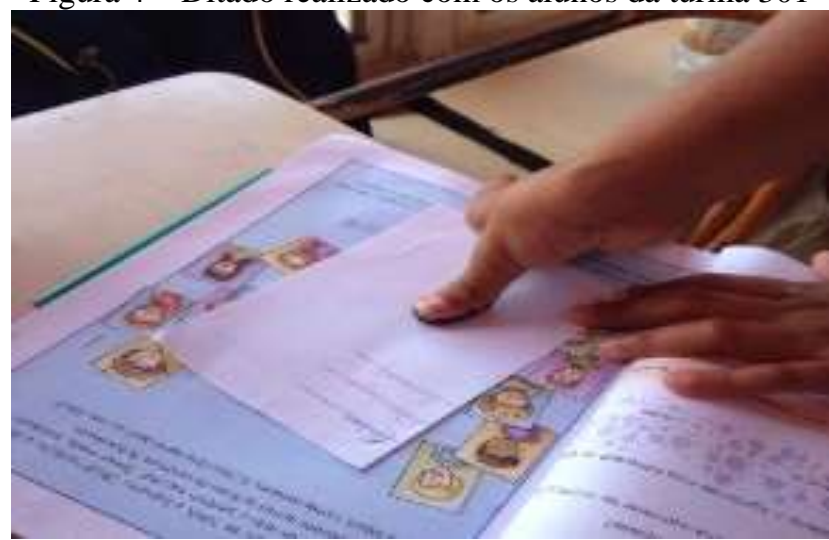

Fonte: Foto tirada pela autora que atua na Escola X (2016)

Figura 5 - Apresentação e discussão das palavras

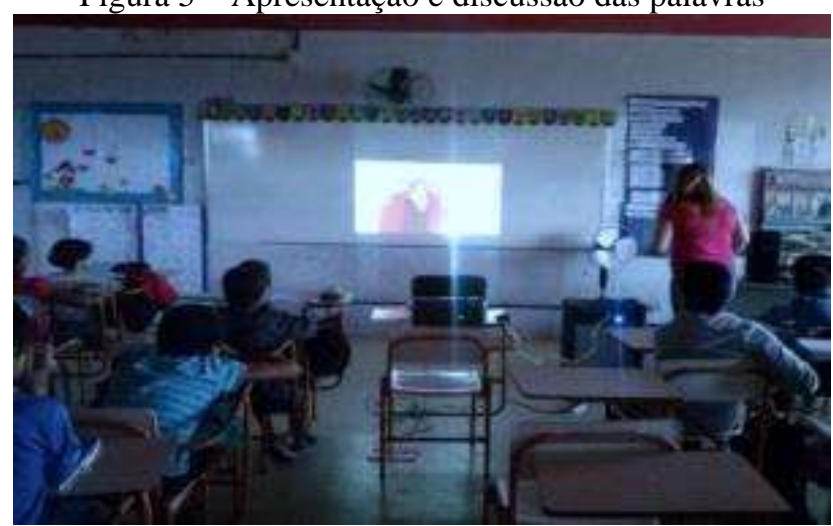

Fonte: Foto tirada pela autora que atua na Escola X (2016)

Figura 6 - Formação das palavras.

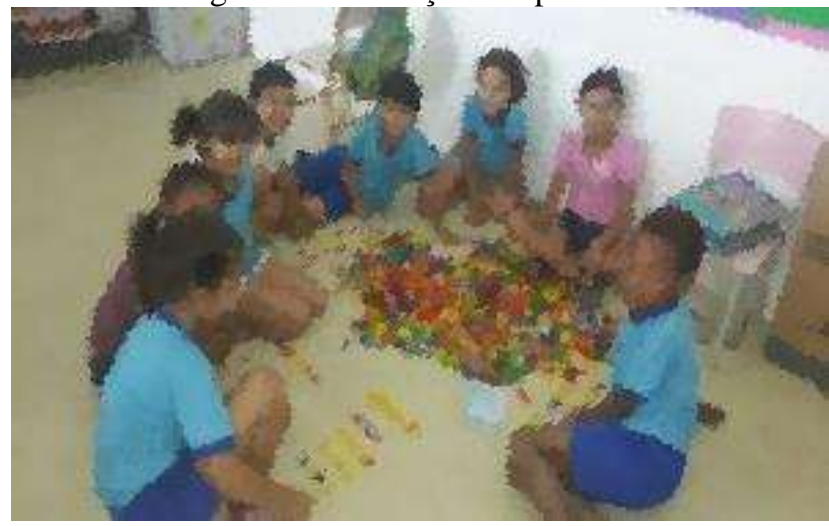

Fonte: Foto tirada pela autora que atua na Escola X (2016). 
Figura 7 - Atividade com as letras das palavras.

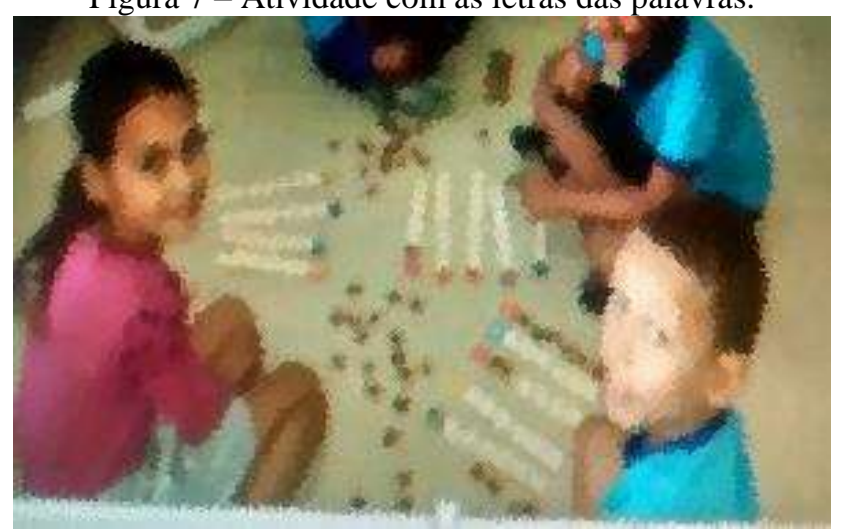

Fonte: Foto tirada pela autora que atua na Escola X (2016).

Após análise do diagnóstico, as sondagens foram discutidas pelas professoras e alunos do curso, gerando muitas sugestões de trabalho. As estratégias apresentadas foram realizadas para oferecer ao professor possibilidades de ampliar seu repertório de práticas no campo da alfabetização e do letramento. Realizamos intervenções para ajudar ao aluno na superação de obstáculos e a progredir na compreensão do funcionamento do sistema de escrita, além de ampliar seu domínio das correspondências grafofônicas e na fluência da leitura.

\section{CONSIDERAÇões FinaIs}

A sondagem da escrita permanente como instrumento de avaliação diagnóstica é de fundamental importância para o desenvolvimento das crianças, auxiliando o professor em sua ação didática, principalmente no trabalho com as dificuldades que os alunos apresentam.

Percebemos que as intervenções dos professores a cada sondagem ajudam as crianças a avançarem de estágio. As crianças que foram observadas apresentaram significativos progressos na escrita e leitura de letras, sílabas e palavras.

É importante frisar que a sondagem deve ocorrer durante o Ciclo de Alfabetização em seus três anos letivos a fim de proporcionar aprendizagens significativas às crianças.

Ressaltamos a importância do curso PNAIC para a implementação de estratégias pedagógicas que permitam às crianças a consolidação das competências e habilidades tanto de leitura quanto de escrita.

\section{REFERÊNCIAS}

BATISTA, Antônio Augusto Gomes; SILVA, Ceris S. Ribas; BREGUNCI, Maria das Graças de Castro; CASTANHEIRA, Maria Lúcia; MONTEIRO, Sara Mourão. Avaliação diagnóstica da alfabetização. Belo Horizonte: Ceale/FaE/UFMG, 2005. 88p. - (Coleção Instrumentos da Alfabetização). Disponível em: < http://www.ceale.fae.ufmg.br/app/webroot/files/uploads/instrumentos\%20da\%20alfabetiza\% 
C3\%A7\%C3\%A3o/Col-Instrumentos-03_AvaliacaoDiagnostica.compressed.pdf>. Acesso em: 28 jan. 2017.

BRASIL. Secretaria de Educação Básica. Diretoria de Apoio à Gestão Educacional. Pacto nacional pela alfabetização na idade certa: formação do professor alfabetizador: caderno de apresentação. Brasília: MEC, SEB, 2012. 40 p. Disponível em:

$<$ http://pacto.mec.gov.br/images/pdf/Formacao/Apresentacao\%20MIOLO.pdf>. Acesso em: 30 nov. 2016.

MACHADO, Maira Gledi Freitas Kelling; STAUB, Teresinha. PNAIC: relatos de experiência de uma formação continuada para a garantia de uma alfabetização de sucesso. IN: Colóquio Internacional de Educação - Educação e contemporaneidade -UFS, 2014, São Cristóvão/SE/Brasil. Anais... São Cristóvão, SE, UFS, 2014, p. 371-380. Disponível em: $<$ http://editora.unoesc.edu.br/index.php/coloquiointernacional/article/view/5147>. Acesso em: 29 jan. 2017.

ONÁRI, Márcia da Rocha, BARROS, Paola Guimarães da La Rocque M. de, BARBOSA, Daniele Corrêa Sales, TRINDADE Vanessa Aguirre. Sondagem: instrumento de avaliação no processo de aprendizagem. In: XV INIC Encontro Latino Americano de Iniciação Científica e XI EPG Encontro Latino Americano de Pós-Graduação - Universidade do Vale do Paraíba, 2011, São José dos Campos, SP. Anais... SJC, SP, UNIVAP, 2011, p. 1-6. Disponível em: <http://www.inicepg.univap.br/cd/INIC_2011/anais/arquivos/0173_1236_01.pdf>. Acesso em: 28 jan. 2017.

Recebido em: 19 e agosto de 2018. Aprovado em: 25 de novembro de 2018. 